\title{
O BNDES E 0 FINANCIAMENTO DO DESENVOLVIMENTO
}

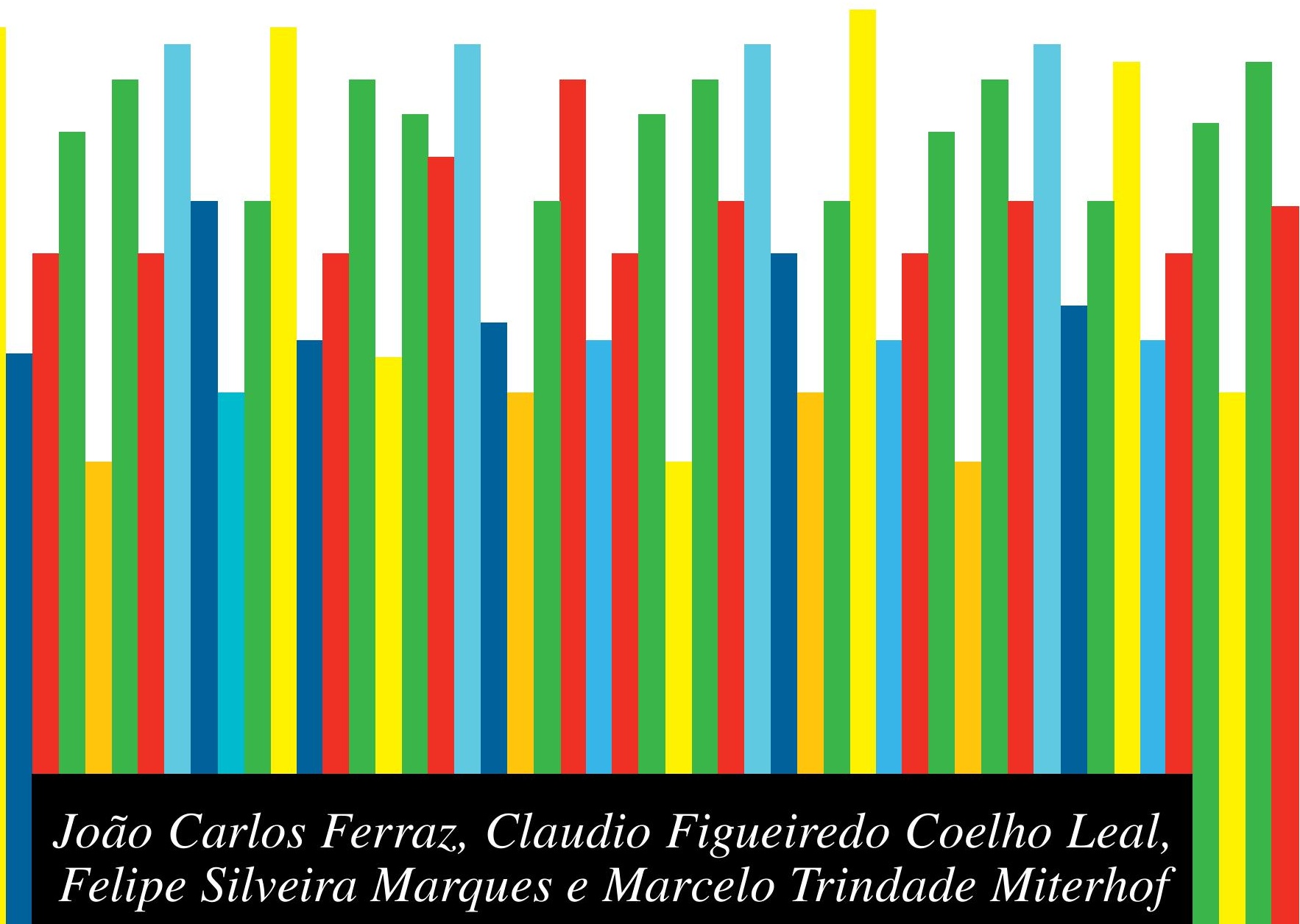


RESUMO

Este artigo analisa a atuação no financiamento de longo prazo do BNDES e também sua recente participação no esforço contracíclico do governo federal para enfrentar os efeitos deletérios da crise financeira internacional sobre o crescimento econômico do país. O texto procura mostrar que a instituição consegue estabelecer e utilizar um amplo leque de instrumentos para responder aos distintos, cambiantes e progressivos desafios do desenvolvimento brasileiro.

Palavras-chave: BNDES, financiamento, desenvolvimento brasileiro.

\section{ABSTRACT}

This article analyzes how BNDES long-term funding works, and also this bank's recent participation in a countercyclical effort by the federal government to buffer the harmful effects of the international financial crisis on the economical growth of the country. The text seeks to demonstrate that this institution has managed to set up and use a wide variety of tools to respond to the diverse, changing and growing challenges to the Brazilian development.

Keywords: BNDES, funding, Brazilian development. 


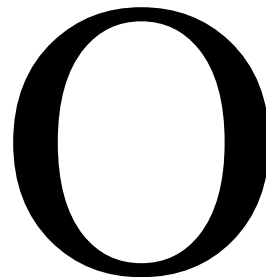

período 2009-11 mostrou a capacidade do Brasil em persistir na trajetória de crescimento que marcou o desempenho econômico nacional de 2005 até o início dos efeitos deletérios da crise financeira internacional sobre o país no segundo semestre de 2008. Não apenas foi possível ao país abreviar, por meio de incisivas iniciativas anticíclicas, a gravidade da crise, como também foram reforçados a determinação do governo e o leque de instrumentos disponíveis para priorizar o longo prazo e sustentar o crescimento do investimento à frente do PIB. De fato, a participação da formação bruta de capital fixo (FBCF) no PIB ampliou-se de 17,4\% em 2007 para 19,3\% em 2011, a despeito da retração observada no final de 2009. Esse nível, porém, é sabidamente insuficiente. É necessário elevar a taxa de investimento no Brasil, sem o que não será possível impulsionar de forma sustentável o crescimento e o enfrentamento dos desafios hoje colocados para a competitividade empresarial.

A atuação do BNDES nesse período combinou o suporte tradicional aos projetos de investimentos e a intervenção anticíclica nos momentos de maior retração do crédito privado. Isso foi possível em função da amplitude de ferramentas do banco, da solidez patrimonial da instituição, que logrou possível a assunção adicional de risco, e da decisão do Tesouro Nacional em prover o banco dos recursos necessários para que não faltasse crédito aos interessados em investir no Brasil.

A atuação anticíclica foi claro exemplo da resposta do BNDES a um desafio conjuntural. A partir dela, o banco se fortaleceu com a ampliação de seu funding e a criação de instrumentos como o Programa de Sustentação do Investimento (PSI).

No ano em que o BNDES comemora seu $60^{\circ}$ aniversário, o objetivo deste artigo é discutir a atuação do banco frente a novos (e também velhos) desafios do país, como o desenvolvimento produtivo, a infraestrutura e a sustentabilidade socioambiental (ou eco- nomia verde). $\mathrm{O}$ artigo está dividido em três seções, além desta introdução. Na segunda seção, apresenta-se a atuação anticíclica verificada no período 2008-09. A terceira seção detém-se nos novos desafios do BNDES, tentando mostrar que eles expressam a dinâmica de mudança associada ao conceito de desenvolvimento. A quarta seção é a conclusão.

\section{A ATUAÇÃO NO PERÍODO RECENTE}

Como instituição financeira controlada integralmente pela União e dotada de fontes estáveis de funding para o desempenho de sua missão, o BNDES vem respondendo, ao longo de sua história, aos desafios de promoção do desenvolvimento econômico e social do país ${ }^{1}$ Esse papel é desempenhado por meio de um conjunto amplo de linhas e programas, capazes de oferecer, numa enumeração não exaustiva, o suporte tradicional aos grandes projetos industriais e de infraestrutura, a promoção da comercialização de máquinas e equipamentos no âmbito do produto Finame, o apoio à exportação de equipamentos e serviços de engenharia, o atendimento às micro e pequenas por meio do Cartão BNDES e o suporte ao mercado de capitais e à governança corporativa das empresas na atuação da BNDESPAR. Dadas as características de constituição de seu funding, o BNDES qualifica-se como a principal fonte de recursos de longo prazo de terceiros disponível para as empresas financiarem seus investimentos ${ }^{2}$, como mostra o Gráfico 1.

Uma consequência importante da institucionalidade de suas fontes é a possibilidade de o BNDES atuar contraciclicamente nos períodos de elevada aversão ao risco das instituições financeiras privadas. A severidade da crise financeira internacional que atingiu a economia brasileira a partir do segundo semestre de 2008, cujos efeitos mais agudos se fizeram sentir até o primeiro trimestre de 2009, exigiu do governo federal o acionamento de diversas ferramentas anticíclicas voltadas para o restabelecimento do crédito. Duas dessas medidas foram especialmente
JOÃO CARLOS FERRAZ, CLAUDIO FIGUEIREDO COELHO LEAL, FELIPE SILVEIRA

MARQUES E MARCELO TRINDADE MITERHOF são economistas do BNDES, respectivamente, vice-presidente, superintendente da Área de Planejamento e assessores

da Presidência.
1 Para uma visão da trajetória recente do BNDES, ver Além e Giambiagi (2010).

2 Segundo dados do Banco Central, o BNDES respondeporcerca de $2 / 3$ do estoque de créditos acima de cinco anos. 
dossiê $\longdiv { \text { Caminhos do desenvolvimento } }$

\section{$\equiv$ \\ GRÁFICO 1}

FONTES DE FINANCIAMENTO PARA O INVESTIMENTO (EM \%)

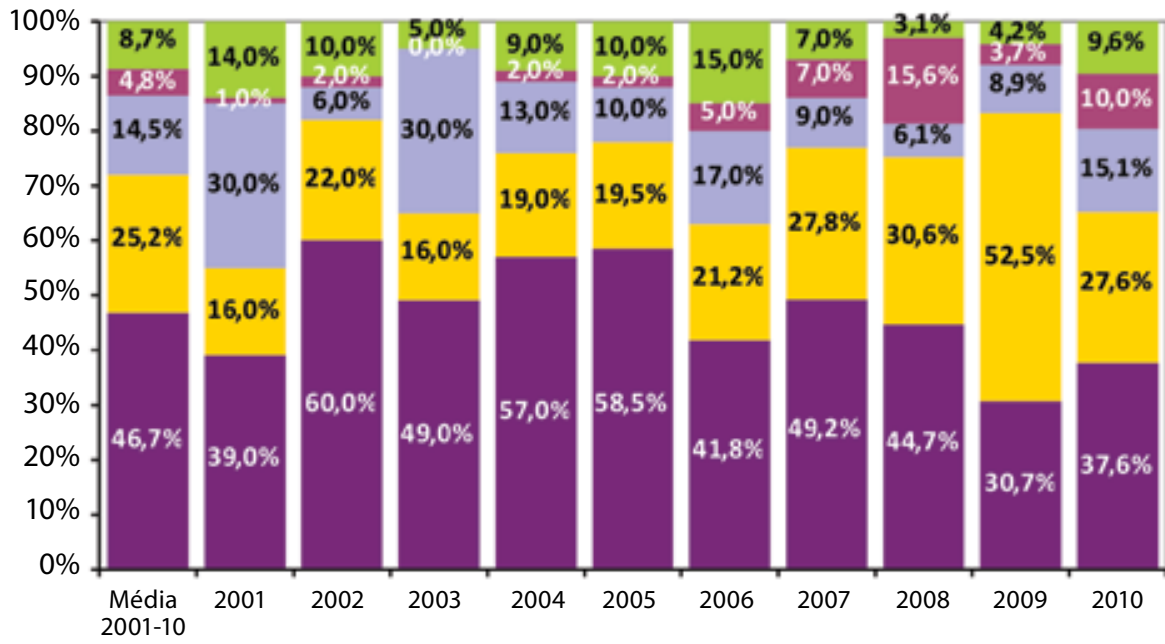

Lucros retidos BNDES Captações externas Ações Debêntures

\section{GRÁFICO 2}

DESEMBOLSO BNDES FINAME E FBCF (3으 TRIM./08 = 100)

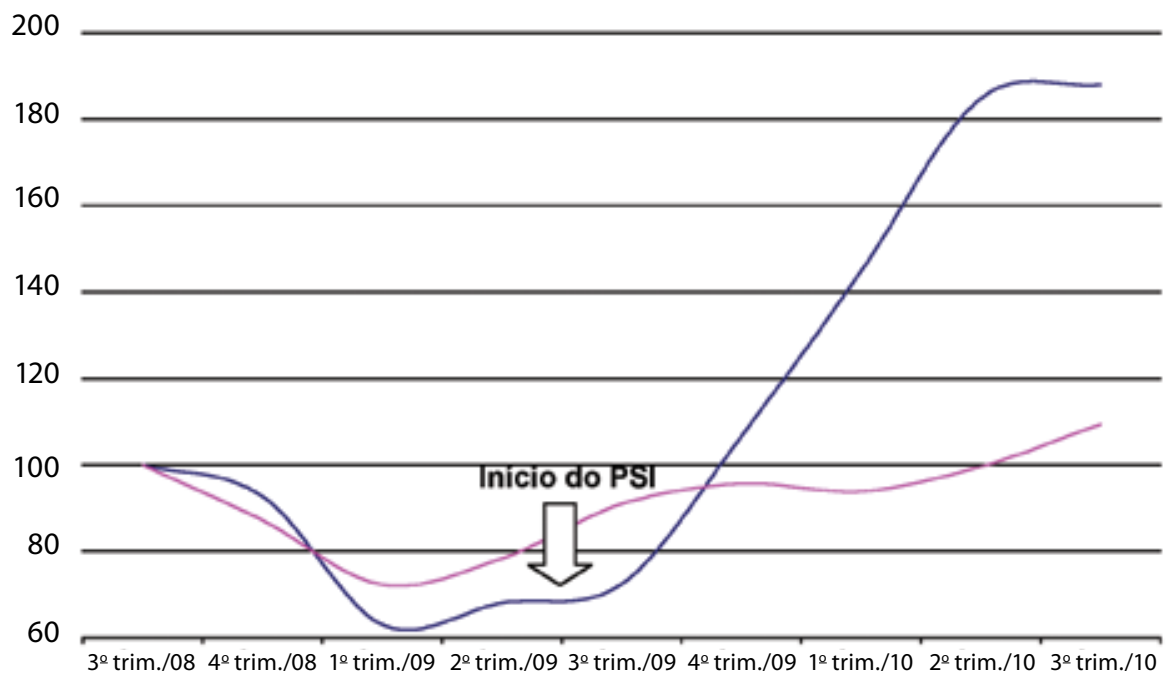

_Desembolso Finame _ FBCF 
relevantes para a ação do BNDES - a criação do Programa de Sustentação do Investimento (PSI), em junho de 2009, e o lançamento de programas extraordinários de apoio ao capital de giro para empresas. A partir desses dois pilares de atuação, que sinalizavam a opção por simultaneamente destravar o crédito de curto prazo e perseguir a retomada do investimento, foi possível ao país suavizar a travessia da crise.

O PSI, hoje na sua terceira versão, consiste em uma linha de financiamento para a aquisição de máquinas e equipamentos a um custo fixado pelo Conselho Monetário Nacional (CMN). Destina-se tanto aos equipamentos isolados financiados pela rede de agentes financeiros do BNDES no âmbito do produto Finame quanto ao subcrédito de bens de capital dos grandes projetos de investimento ${ }^{3}$. O início do programa, em junho de 2009, lança uma luz importante sobre o momento adequado de resposta aos desafios conjunturais. Talvez a potência do programa não tivesse sido de imediato plenamente observada caso seu lançamento tivesse ocorrido ainda no segundo semestre de 2008, quando o investimento experimentava forte retração. Essa noção é apresentada no Gráfico 2, que mostra a infle- xão da trajetória dos desembolsos da Finame após o lançamento do PSI e o comportamento da formação bruta de capital fixo (FBCF).

Paralelamente ao esforço de sustentação do investimento ao longo de uma conjuntura francamente adversa entre o final de $2008 \mathrm{e}$ durante o ano de 2009, a ação dos bancos públicos foi também decisiva no fornecimento de crédito de curto prazo às empresas. Extrapolando circunstancialmente o seu papel tradicional de provedor de recursos de longo prazo, o BNDES, nesse período, foi convocado a conceber linhas extraordinárias de capital de giro - ainda que não associadas a projetos de investimento. Tratava-se de programas de prazo mais curto e custo mais elevado do que as linhas usuais do banco e, adicionalmente, limitados pelo porte das empresas tomadoras e, no caso de alguns programas, direcionados a setores específicos. O Quadro 1 lista algumas das iniciativas do BNDES relacionadas ao esforço de fornecimento de capital de giro e manutenção de investimentos, que depois foram encerradas com a melhoria do cenário interno.

No período recente, o BNDES vem respondendo à rápida evolução do investimento por meio da ampliação de seus desembolsos
3 Na sua primeira versão, o custo final do PSI para as empresas era de $4,5 \%$. Sucessivas revisões do programa, além de estenderemoescopo de atuação origina para outras finalidades, notadamente o apoio à inovação, elevaram o custo para cerca de $9 \%$ ao ano. Nesse nível, não há mais necessidade de equalização do Tesouro Nacional.

\section{QUADRO 1}

\section{MEDIDAS SELECIONADAS DO BNDES DE COMBATE À CRISE}

\begin{tabular}{|c|c|}
\hline out./08 & Ampliação do acesso ao Pré-embarque \\
\hline nov./08 & Criação do BNDES PEC (Programa Especial de Crédito) \\
\hline jan./09 & Ampliação do Refin \\
\hline fev./09 & Criação do Programa BK Usados \\
\hline abr./09 & Criação do BNDES PEF (Programa Emergencial de Financiamento) \\
\hline abr./09 & Criação do BNDES Procer (Programa de Crédito Especial Rural) \\
\hline abr./09 & Melhoria das condições do produto BNDES Pré-embarque \\
\hline abr./09 & Melhoria das condições do produto BNDES Empréstimo-ponte \\
\hline jun./09 & Criação do BNDES Refin - BK \\
\hline
\end{tabular}

Fonte: BNDES 


\section{DESEMBOLSO DO BNDES E FBCF (EM R\$ BILHÕES)}

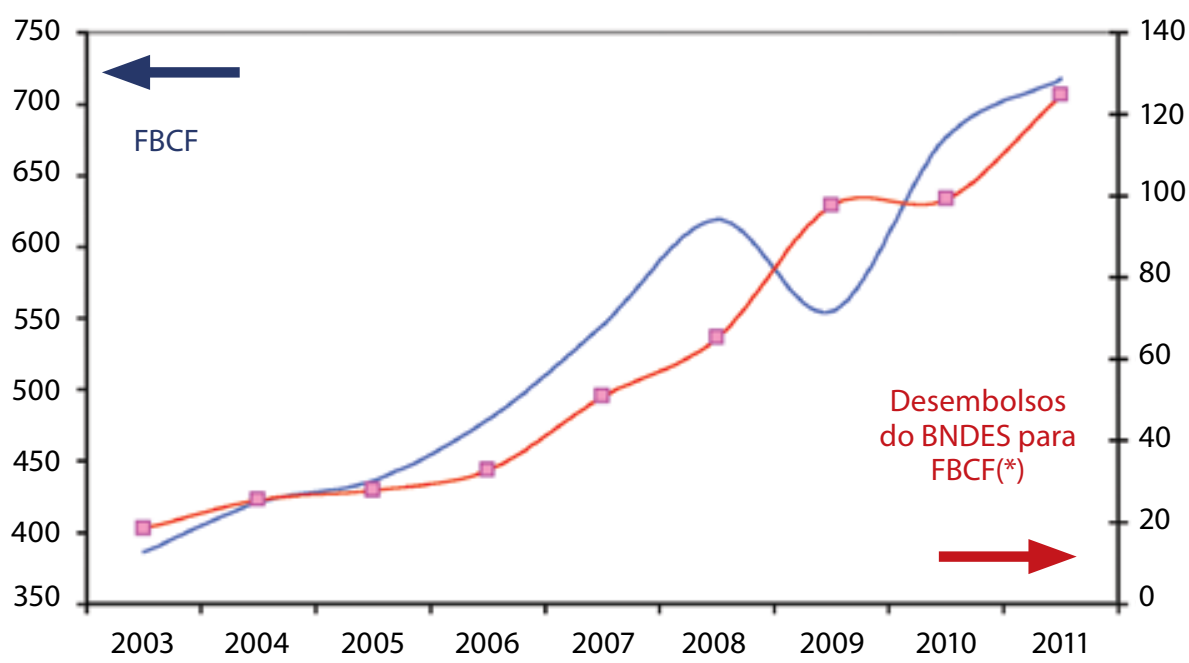

$\left(^{*}\right)$ exclui Exim Pré e Pós; Giro, Ajuste Fiscal, Fusão/Aquisição; Internacionalização e Mercado de Capitais

4 Para uma visão histórica da atuação do BNDES, ver BNDES (2002).

5 Os sistemas da mecânica, eletroeletrônica esaúde equivalemao Bloco 1 do Plano Brasil Maior e correspondem aos seguintes setores: petróleo \& gás e naval (cadeia de suprimento);complexo da saúde (fármacos, medicamentos, equipamentos médicos e hospitalares e serviços de saúde); automotivo;aeronáutico e complexo de defesa eaeroespacial bens de capital; e eletroeletrônica e tecnologias da informação e comunicação(TICs).

6 São eles: químico; energias renováveis; higiene pessoal, perfumaria e cosméticos (HPPC); mineração; metalúrgico; e celulose e papel.

Fonte: BNDES e IBGE

para a formação de capital fixo. O Gráfico 3 mostra que as liberações do BNDES acompanham em grandes linhas a trajetória do investimento na economia.

\section{NOVOS (E VELHOS) DESAFIOS}

Para além de sua atuação anticíclica, o BNDES, como banco público voltado para o longo prazo, tem sempre a missão de apoiar investimentos prioritários para a economia brasileira. A história do banco é continuamente marcada pela incorporação de novas preocupações ${ }^{4}$. Alguns temas estão presentes na sua atuação há várias décadas, como o de ampliar o investimento e o de financiar projetos de infraestrutura. A criação da infraestrutura econômica, em especial energia e transportes, marcou os anos de 1950. A indústria de base foi o destaque nos anos de 1960 enquanto os insumos básicos e bens de capital foram as principais áreas incorporadas nos anos de 1970. Da mesma maneira, novos objetivos se incorporaram à agenda prioritária do BNDES nas últimas décadas, como o de fomentar a inovação, o de promover a sustentabilidade socioambiental, o de apoiar a modernização da gestão pública e o de incentivar o desenvolvimento local, a inclusão produtiva e a ampliação do acesso ao crédito.

Esses temas ilustram o significado do velho conceito de desenvolvimento, que associa o crescimento econômico com o bem-estar social, a inovação e a competitividade. As preocupações contemporâneas fizeram esse conceito ter seu significado ampliado, sob a insígnia da sustentabilidade, de maneira a incorporar temas como o da preservação ambiental e o uso mais eficiente e responsável dos recursos naturais, o que também pode ser chamado de economia verde.

Nesse sentido, vale a pena destacar o desempenho recente do BNDES em três áreas ou atividades: o desenvolvimento produtivo, a infraestrutura e a sustentabilidade socioambiental (ou economia verde).

\section{Desenvolvimento produtivo}

As ações do banco para estimular o crescimento industrial do país visam a dar conta 
de três grandes desafios: ampliar a capacidade produtiva da indústria e do setor de serviços; aumentar as exportações; e elevar a capacidade de inovação, fator essencial para o crescimento em um mundo globalizado. Desde 2006, o BNDES vem ampliando sua atuação nessas áreas, em consonância com as políticas industriais elaboradas no período: a Política Industrial, Tecnológica e de Comércio Exterior (PITCE, 2004-07), a Política de Desenvolvimento Produtivo (PDP, 2008-10), e o Plano Brasil Maior (PBM, 2011-14). Esse crescimento não sacrificou os setores prioritários (sistemas da mecânica, eletroeletrônica e saúde ${ }^{5}$ ), que mantiveram sua participação de cerca de 1/3 no desembolso total, número esse que se eleva a $55 \%$ com a contabilização do apoio à aquisição de bens de capital por outros sistemas produtivos. $\mathrm{O}$ maior efeito da crise internacional sobre o desembolso do BNDES no apoio ao setor produtivo foi uma pequena perda de participação relativa dos sistemas intensivos em escala ${ }^{6}$ e agronegócio, que são mais voltados para o mercado externo. A contrapartida foi o aumento da participação do comércio, logística e serviços, segmentos voltados para o mercado interno, que lideraram o crescimento no período.

Ao longo do período, diversos programas foram criados/alterados para favorecer a agregação de valor local. Dentre eles, destacam-se o PSI, comentado anteriormente, o apoio a projetos de inovação (Funtec, Criatec, Capital Inovador, Inovação Produção, Proengenharia, Cartão BNDES, etc. ${ }^{7}$ ) e os programas setoriais do BNDES, que oferecem condições especiais de crédito para setores intensivos em conhecimento, como Pró-P\&G (cadeia de fornecedores de petróleo e gás), Prosoft (software e serviços de tecnologia da informação), Profarma (complexo industrial da saúde), Proplástico (cadeia produtiva do plástico) e Pro-aeronáutica (cadeia produtiva aeronáutica).

\section{GRÁFICO 4}

\section{DESEMBOLSO DO BNDES PARA SISTEMAS PRODUTIVOS (EM R\$ BILHÕES)}

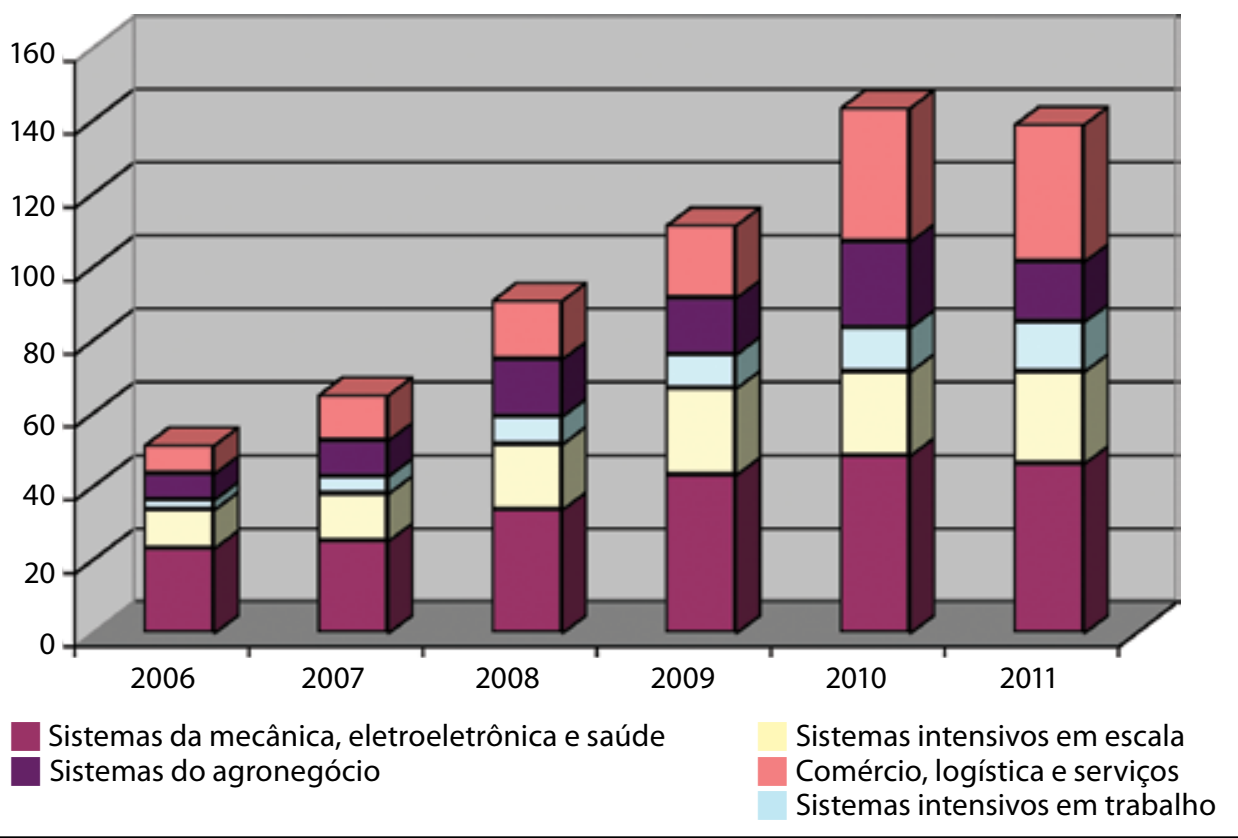

Fonte: BNDES

7 Em linhas gerais, o apoio do bancoà inovação, definida como prioridade no âmbito do seu planejamento corporativo, assenta-se sobre um tripé de linhas de crédito reembolsáveis, apoio não reembolsável no âmbito do Funtec e subscrição de ações e debêntures conversíveis diretamente ou por meio de fundos. Mais recentemente, foram também celebrados contratos de empréstimo e de abertura de limite de crédito para repasse das linhas de inovaçãocoma Finep. A ação coordenada dessas três fontes é fundamental para potencializar a eficácia da utilização dosrecursos públicos, buscando-se combinar, de um lado, o desafio não trivia de ampliar a base de empresasinovadoras e, de outro, apoiar projetos estruturantes que mobilizem capacidades técnicas e empresariais nas áreas em que o país já dispõe ou pode construir vantagens competitivas. A esse respeito, cabe destacar a iniciativa conjunta do BNDES e da Finep com o Programa de Apoio à Indústria Sucroalcooleira (Paiss), que, por meio de chamada pública buscou selecionar planos de negócio para o desenvolvimento da produção de etanol de segunda geração (também denominado etano celulósico). Para uma reflexãosobreoapoio do BNDESà inovação, ver Kickinger e Veiga de Almeida (2010). 


\section{MEDIDAS SELECIONADAS DE APOIO AO DESENVOLVIMENTO PRODUTIVO E TECNOLÓGICO (JAN./06-JAN./12)}

\begin{tabular}{|c|c|}
\hline dez./06 & $\begin{array}{l}\text { Criação do Programa de Modernização de Máquinas e Equipamentos } \\
\text { (Finame Moderniza BK); e criação do Programa Finame de aquisição } \\
\text { de peças, partes e componentes de fabricação nacional, } \\
\text { por fabricantes de bens de capital (Finame-Componentes) }\end{array}$ \\
\hline dez./06 & $\begin{array}{l}\text { Criação do Criatec, fundo de investimento em empresas } \\
\text { nascentes voltadas para inovação }\end{array}$ \\
\hline jun./07 & Criação do Programa de Apoio à Engenharia Automotiva \\
\hline ago./07 & Criação do Proaeronáutica \\
\hline set./07 & $\begin{array}{l}\text { Ampliação do Programa de Apoio ao Desenvolvimento da Cadeia Produtiva } \\
\text { Farmacêutica (Profarma), renomeado Programa de Apoio } \\
\text { ao Desenvolvimento do Complexo Industrial da Saúde (Profarma) }\end{array}$ \\
\hline jan./08 & Criação da linha Capital Inovador \\
\hline jun./09 & Criação do Programa de Apoio à Engenharia (Proengenharia) \\
\hline jul./09 & Criação do Programa BNDES de Sustentação do Investimento (BNDES PSI) \\
\hline set./09 & $\begin{array}{l}\text { Ampliação do BNDES Prosoft, com aumento de dotação orçamentária, } \\
\text { e apoio a investimentos em ITES-BPO }\end{array}$ \\
\hline dez./09 & Criação da Linha Inovação - Produção \\
\hline jun./10 & $\begin{array}{l}\text { Criação do Programa BNDES de Apoio ao Desenvolvimento } \\
\text { da Cadeia Produtiva do Plástico (BNDES Proplástico) }\end{array}$ \\
\hline nov./10 & $\begin{array}{l}\text { Apoio a projetos de pesquisa, desenvolvimento } \\
\text { e inovação no âmbito do Produto BNDES Automático. }\end{array}$ \\
\hline mar./11 & $\begin{array}{l}\text { Lançamento do Plano Conjunto BNDES-Finep de Apoio à Inovação } \\
\text { Tecnológica Industrial dos Setores Sucroenergético e Sucroquímico (Paiss) }\end{array}$ \\
\hline mar./11 & Empréstimo de R\$ 1 bilhão para apoio à carteira de inovação da Finep \\
\hline mai./11 & $\begin{array}{l}\text { Criação do Programa BNDES de Apoio ao Desenvolvimento } \\
\text { da Cadeia de Fornecedores de Bens e Serviços relacionados } \\
\text { ao setor de Petróleo e Gás Natural (BNDES P\&G) }\end{array}$ \\
\hline
\end{tabular}
out./11 Alteração das políticas operacionais do BNDES para favorecer o conteúdo local e a inovação
out./11 Criação do Programa BNDES de Apoio à Qualificação Profissional (BNDES Qualificação)

nov./11 Empréstimo de R\$ 2 bilhões para apoio à carteira de inovação da Finep 


\section{Infraestrutura}

Ainda que nem sempre seja claro qual o sentido de causalidade, não há dúvidas acerca da forte correlação entre desenvolvimento econômico e oferta de infraestrutura, que em geral se reforçam mutuamente. A solução dos problemas de infraestrutura é condição necessária para a melhoria do bem-estar da população, permitindo que todos tenham acesso a serviços básicos como energia elétrica, comunicações, transportes urbanos e saneamento. Ao mesmo tempo, a ampliação da infraestrutura promove redução de custos, aumento da produtividade, aprimoramento da qualidade dos bens e serviços da estrutura produtiva e consolidação da integração regional.

O BNDES sempre atuou nessa área. Nos últimos anos, porém, houve um expressivo aumento dos desembolsos do BNDES, o que se deveu ao crescimento econômico e à participação de destaque do banco no Programa de Aceleração do Crescimento (PAC).

Ao longo do período, diversos programas foram criados ou alterados para fomentar in- vestimentos em infraestrutura. Dentre eles, destaca-se a criação, em fevereiro de 2008, do Fundo Estruturador de Projetos (FEP) que provê financiamentos não reembolsáveis a estudos de ampla divulgação pública que contribuam para a formulação de políticas públicas ou a geração de projetos relacionados ao desenvolvimento econômico e social do Brasil e da América Latina - e a criação em novembro de 2009 da Linha BNDES Estados, voltada a apoiar a formulação e a implantação de programas de desenvolvimento integrado dos estados brasileiros.

\section{Sustentabilidade socioambiental}

O desenvolvimento socioambiental é uma prioridade corporativa que se reflete na política de financiamentos do banco. No entanto, em que pese o esforço recente de construção de linhas específicas com foco ambiental, a maior parte do desembolso relacionado à redução de emissões de carbono está nos setores de energia e transporte, que

\section{GRÁFICO 5}

\section{DESEMBOLSO DO BNDES PARA INFRAESTRUTURA (EM R\$ BILHÕES)}

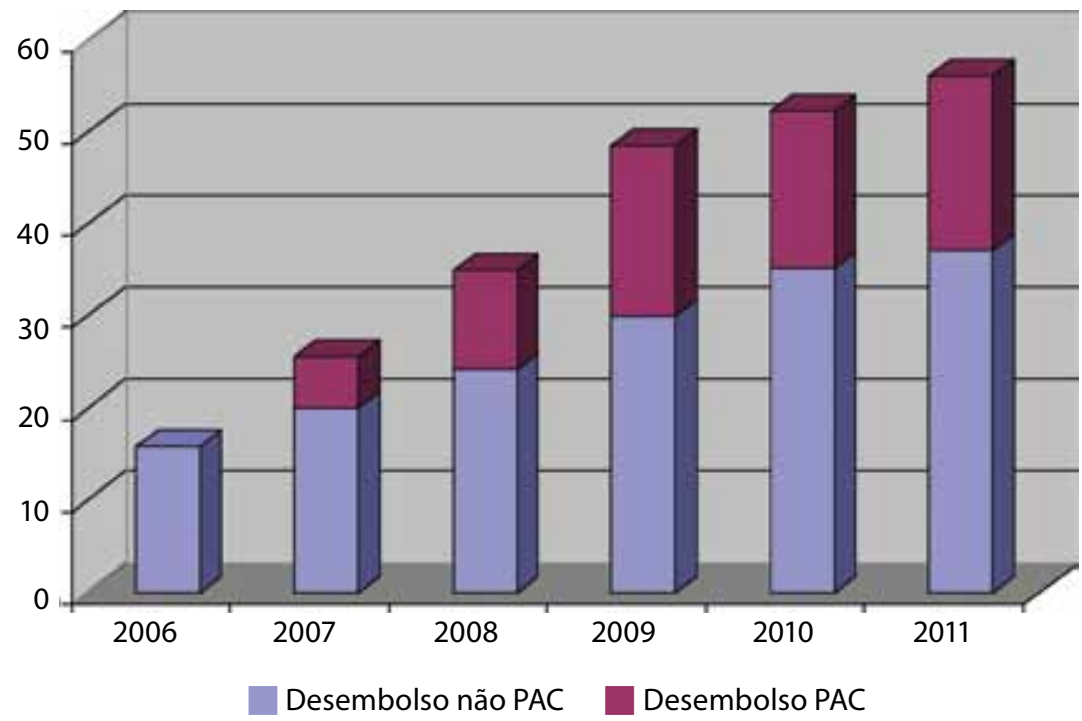

Fonte: BNDES 


\section{MEDIDAS SELECIONADAS DE APOIO À INFRAESTRUTURA (JAN./06-JAN./12)}

\begin{tabular}{|c|c|}
\hline mar./06 & $\begin{array}{l}\text { Criação do Programa BNDES de Financiamento a Caminhoneiros } \\
\text { (BNDES Procaminhoneiro) }\end{array}$ \\
\hline abr./06 & Criação do Programa de Intervenções Viárias (Provias) \\
\hline dez./06 & $\begin{array}{l}\text { Criação do Programa de Apoio à Implementação do Sistema Brasileiro } \\
\text { de TV Digital Terrestre (PROTVD) }\end{array}$ \\
\hline mar./07 & $\begin{array}{l}\text { Criação da Linha de Modernização da Administração das Receitas } \\
\text { e Gestão Fiscal, Financeira e Patrimonial das Administrações Estaduais }\end{array}$ \\
\hline mar./07 & Criação do Programa Caminho da Escola \\
\hline mai./07 & $\begin{array}{l}\text { Criação do Programa de Financiamento à Aquisição de Veículo } \\
\text { de Transporte Escolar (Proescolar) }\end{array}$ \\
\hline fev./08 & Criação do Fundo Estruturador de Projetos (BNDES FEP) \\
\hline mar./09 & $\begin{array}{l}\text { Criação do Programa Especial de Apoio ao Setor de Petróleo e Gás; } \\
\text { Criação do programa BNDES Construção Civil e inclusão de insumos } \\
\text { para a construção civil no Cartão BNDES }\end{array}$ \\
\hline nov./09 & Criação da Linha de Financiamento BNDES Estados \\
\hline jul./10 & Apoio ao Programa Um Computador por Aluno (Prouca) \\
\hline ago./10 & $\begin{array}{l}\text { Alteração de condições nas linhas "energia elétrica" e "energias renováveis", } \\
\text { com aumento da participação do BNDES e ampliação do prazo de amortização }\end{array}$ \\
\hline out./11 & $\begin{array}{l}\text { Criação do Programa BNDES Emergencial de Reconstrução } \\
\text { de Municípios Afetados por Desastres Naturais (BNDES PER) }\end{array}$ \\
\hline
\end{tabular}

Fonte: BNDES

foram os primeiros focos de atuação do $\mathrm{BN}$ DES. O recente crescimento do desembolso verde também está em boa parte relacionado a esses setores, como energia hidrelétrica e eólica ${ }^{8}$, beneficiados pelo PAC. A implementação do PAC Mobilidade Grandes Cidades, com foco nas cidades-sede da Copa do Mundo, deve elevar significativamente o desembolso relacionado a transporte urbano.

O BNDES, por meio de diversas inicia-

8 Em 2011, pelaprimeira vez, os desembolsos do BNDES para projetos de geração eólica superaramaqueles de geração hidrelétrica. gestor do Fundo Amazônia, desde 2008, e, mais recentemente, a designação por parte do Ministério do Meio Ambiente (MMA) para a gestão do Fundo Nacional de Mudanças Climáticas (Fundo Clima). Em ambos os casos, também se evidencia a habilitação do BNDES, aprofundada pela criação da referida Área de Meio Ambiente, para o desempenho do papel de gestor de fundos externos relacionados à economia verde, uma competência que a BNDESPar já havia demonstrado ao conceber diversos fundos voltados para investimentos sustentáveis e ao liderar, em conjunto com a BM\&F-Bovespa, a criação do índice carbono-eficiente de ações em 2010. 


\section{GRÁFICO 6}

\section{DESEMBOLSO DO BNDES PARA A ECONOMIA VERDE (EM R\$ BILHÕES)}

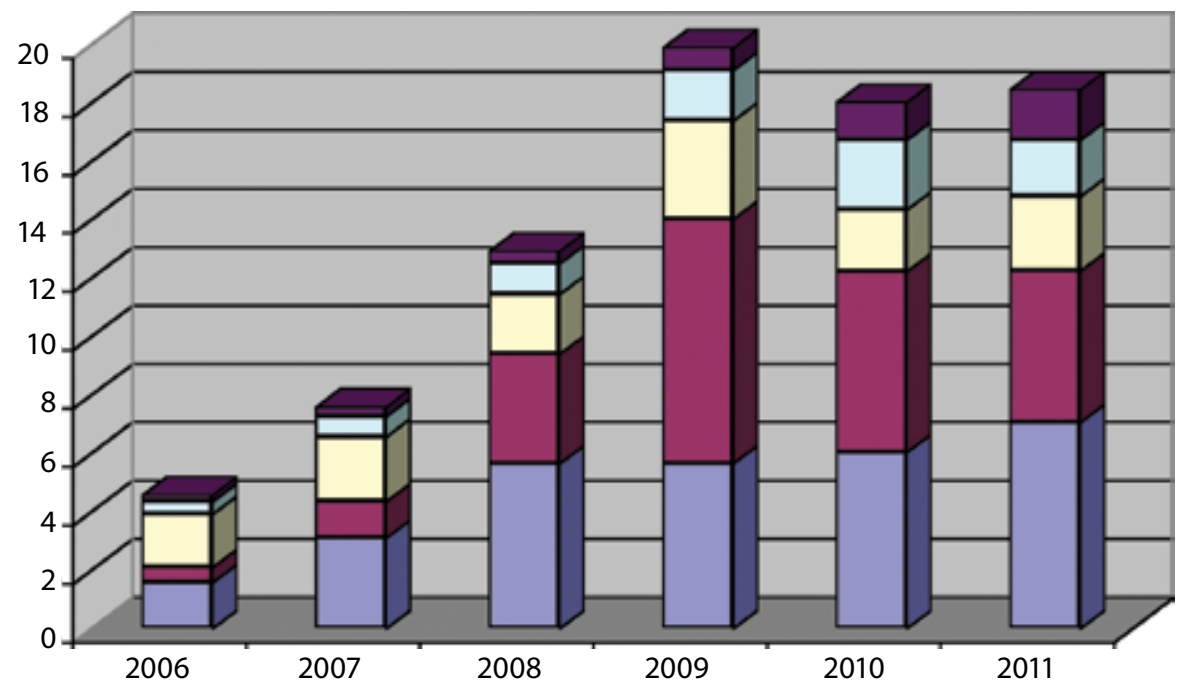

Energias renováveis e eficiência energética

Gestão de água, esgoto e resíduos sólidos

Hidrelétricas (acima de $30 \mathrm{MW}$ )

Florestas, melhorias agrícolas e outros

Fonte: BNDES

\section{QUADRO 4}

\section{MEDIDAS SELECIONADAS DE APOIO À ECONOMIA VERDE (JAN./06-JAN./12)}

\begin{tabular}{|c|c|}
\hline mai./06 & Criação da Linha de Meio Ambiente \\
\hline mai./06 & Criação da Linha para Apoio a Projetos de Eficiência Energética (Proesco) \\
\hline jun./07 & Criação do Programa BNDES Desenvolvimento Limpo \\
\hline ago./08 & $\begin{array}{l}\text { Criação do Programa de Estímulo à Produção Agropecuária Sustentável } \\
\text { (Produsa) }\end{array}$ \\
\hline set./08 & Criação do Fundo Amazônia \\
\hline abr./09 & Constituição da Iniciativa Mata Atlântica \\
\hline jul./09 & $\begin{array}{l}\text { Criação do Programa BNDES de Apoio à Compensação Florestal } \\
\text { (BNDES)Compensação Florestal; e alteração da Linha de Meio Ambiente - } \\
\text { Apoio à Recuperação Florestal de Carajás - Refloresta, } \\
\text { que passa a ser denominada Linha de Apoio ao Reflorestamento, } \\
\text { Recuperação e Uso Sustentável das Florestas (BNDES Florestal). }\end{array}$ \\
\hline jul./10 & $\begin{array}{l}\text { Criação do Programa de Estímulo à Produção Agropecuária Sustentável } \\
\text { (Produsa) }\end{array}$ \\
\hline out./11 & $\begin{array}{l}\text { Criação do Programa para Redução da Emissão de Gases de Efeito Estufana } \\
\text { Agricultura (Programa } A B C \text { ) }\end{array}$ \\
\hline jun./11 & Criação do Programa BNDES Fundo de Inovação em Meio Ambiente \\
\hline nov./11 & Criação do Programa Fundo Clima \\
\hline
\end{tabular}




\section{CONCLUSÃO}

A trajetória do BNDES nos últimos anos mostra um substancial salto na sua capacidade de desembolso ocorrido em razão dos aportes de recursos do Tesouro Nacional. Espera-se que o banco estabilize o crescimento de seus desembolsos a partir do patamar de $\mathrm{R}$ \$ 140 bilhões. Esse patamar significa uma maior capacidade de atuação do BNDES tanto para fazer frente a desafios conjunturais, como ocorreu diante da recente crise financeira internacional, quanto para perseguir os desafios estruturais associados ao desenvolvimento, intensificando o apoio a setores que sempre estiveram no radar de prioridades do banco, como a infraestrutura, e também buscando atender a novos objetivos, como são os casos da sustentabilidade ambiental e da incorporação de novas preocupações ao desenvolvimento produtivo (inovação e desenvolvimento regional).

Por ser uma das mais importantes instituições brasileiras de promoção do desenvolvimento, é alvissareiro constatar que o BNDES tem hoje uma capacidade de atuação substancialmente maior do que há quatro ou cinco anos. Mas as perspectivas e os desafios do desenvolvimento nacional evidentemente não se restringem apenas ao banco. Pelo contrário, exigem a articulação de múltiplos atores. É evidente, por exemplo, a constatação de que o país está diante de robustos blocos de investimento que demandam arranjos e estruturas de financiamento em escala muito superior à capacidade de atuação do BNDES.
Nesse sentido, em meio a incertezas quanto aos desdobramentos da crise econômica internacional, o banco tem o duplo desafio de persistir na sua missão de assegurar financiamento para as múltiplas preocupações e setores associados ao desenvolvimento do Brasil e, ao mesmo tempo, de estimular fontes privadas de recursos de longo prazo, que venham se somar ao esforço de incrementar a taxa de investimento do país. Esse foi sempre um esforço perseguido pelo BNDES, mas que deverá ter um novo e decisivo impulso com a convergência das taxas de juros internas para o padrão internacional.

Além disso, o sucesso brasileiro na indústria extrativista e no agronegócio, alavanca fundamental do desenvolvimento, deve ser referência para a indústria de transformação. Assim, alguns desafios de desenvolvimento produtivo farão parte da agenda prioritária do BNDES nos próximos anos. Um deles será o de apoiar as vendas externas de bens e serviços intensivos em engenharia para diversificar a pauta de exportações. Outro será reforçar a competitividade dos fornecedores de partes, peças e componentes da indústria de transformação, com destaque para a cadeia de petróleo e gás. Também serão relevantes novos projetos ligados a indústrias como a farmacêutica e a de tecnologias de informação e comunicação (TICs).

Frente a esses novos (e velhos) desafios, o BNDES deve persistir no apoio aos investimentos prioritários para a economia brasileira. Missão essa que desempenhou com visão de longo prazo, espírito público e excelência técnica ao longo de seus sessenta anos de história.

\section{BIBLIOGRAFIA}

ALÉM, A. C.; GIAMBIAGI, F. (orgs.). O BNDES em um Brasil em Transição. Rio de Janeiro, BNDES, 2010.

BNDES. BNDES: 50 Anos de Desenvolvimento. São Paulo, DBA Artes Gráficas, 2002. KICKINGER, F. C.; VEIGA DE ALMEIDA, H. T. "Reflexões sobre a Inovação no Brasil e o Papel do BNDES", in Além \& Giambiagi. O BNDES em um Brasil em Transição. Rio de Janeiro, BNDES, 2010. 